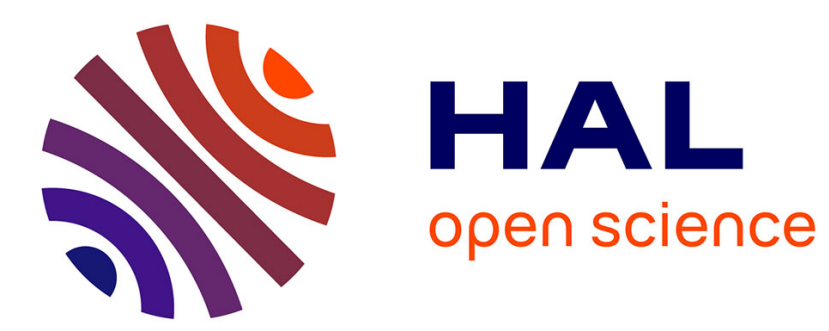

\title{
ELECTROMECHANICAL EFFECTS OF PULSED LASERS
}

J. Laurent, J. Englender, A. Antonetti, Y. Lecarpentier

\section{To cite this version:}

J. Laurent, J. Englender, A. Antonetti, Y. Lecarpentier. ELECTROMECHANICAL EFFECTS OF PULSED LASERS. Journal de Physique IV Proceedings, 1991, 01 (C7), pp.C7-193-C7-197. 10.1051/jp4:1991752 . jpa-00250994

\section{HAL Id: jpa-00250994 https://hal.science/jpa-00250994}

Submitted on 1 Jan 1991

HAL is a multi-disciplinary open access archive for the deposit and dissemination of scientific research documents, whether they are published or not. The documents may come from teaching and research institutions in France or abroad, or from public or private research centers.
L'archive ouverte pluridisciplinaire HAL, est destinée au dépôt et à la diffusion de documents scientifiques de niveau recherche, publiés ou non, émanant des établissements d'enseignement et de recherche français ou étrangers, des laboratoires publics ou privés. 


\title{
ELECTROMECHANICAL EFFECTS OF PULSED LASERS
}

\author{
J.Ph. LAURENT, J. ENGLENDER, A. ANTONETTI and Y. LECARPENTIER \\ Institut National pour la Santé et la Recherche Médicale, Unité 275, LOA-ENSTA, \\ Ecole Polytechnique, F-91128 Palaiseau, France
}

\begin{abstract}
A theoritical study of the electromechanical effects of pulsed lasers on biological tissues is presented.The initiation of the plasma is more likely due to a thermal effect (heating and ionization of the gas) than to a multiphotonic process (simultaneous action of several light quanta). The mechanism of expansion of the plasma by inverse bremsstrahlung is described. The shock waves and the gas bubble generated by the ultra fast expansion of the plasma are studied. Theoritical results fit the experimental observations and permit to conclude that electromechanical effects are the main process during the fragmentation of the calculi and are quite useful during the ablation of atheroma.
\end{abstract}

\section{INTRODOCTION}

Because it was considered as an accurate, powerful and handy tool by the physicians, the laser has been used in medecine for nearly 15 years. The control of the wavelength, of the energy, and of the irradiation duration allows to select the convenient interaction with biological tissues among a wide range of actions : the thermal effects which consist in the vaporization (sometimes only the alteration) of the target tissues; the photoablative effect which is the direct dissociation of molecular links by ultra-violet photons (by excimer lasers); the photochemical effects which permit a selective action on tissues; and the electromechanical effects, the origin of which is a laser induced breakdown and the formation of a plasma. Only pulsed lasers can realize mechanical actions, because of the high fluences (Watts per square centimeter) it needs to create a plasma.

In order to study this process, we use a Nd:YAG laser $(\lambda=1,064 \mu \mathrm{m})$ built in association with the firm Quantel. We can regulate the pulse duration from $300 \mathrm{~ns}$ to $2500 \mathrm{~ns}$, using a total energy of around $100 \mathrm{~mJ}$ or $200 \mathrm{~mJ}$. Our target tissues (atheroma or calculi) are put either in the air (and then we focalized the laser beam on the surface of the target); or in water (we transmit light by optic fibers, without focalizing the beam). The diameter of the optic fibers we used is between $200 \mu \mathrm{m}$ and $400 \mu \mathrm{m}$. So that the mean power of the pulses is roughly $P=10^{5} \mathrm{~W}$, which leads to an average fluence of $F=6 \times 10^{8} \mathrm{~W} / \mathrm{cm}^{2}$. Such features of the incident light can create in the tissues an alternative field, the amplitude of which is

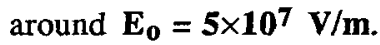

The global process consists of initiation and growth of the plasma, followed by generation of shock waves and a cavitation mechanism which can fragment and vaporize the tissues.

The energy supplied by the laser can heat and vaporize the cold matter. Then the gases formed can be partially ionized by thermal effects. The free electrons thus created are accelerated by the electromagnetic field (by the inverse bremsstralhung mechanism) until they acquire an energy as high as the ionization energy of the atom. They can then ionize an atom by inelastic collision, loosing their energy and creating other free electrons.

The ultra fast growth of the plasma generates shock waves of pressure and temperature. These shock waves create a gas bubble which grows and collapses, emitting a depression wave. All these mechanisms are responsible for the destruction and the ablation of the tissues. 


\section{2- INTTIATION OF THF PTASMA}

The expansion of the plasma, mostly leaded by the inverse bremsstralhung mechanism, need a few free electrons in the focal volume to be initiated. Both the thermal and the multiphotonic ionization can explain the formation of the first free electrons. Yet, the multiphotonic ionization needs a much higher incident fluence than the one we use in our experiments $\left(F=6 \times 10^{8} \mathrm{~W} / \mathrm{cm}^{2}\right)$.

\section{Multiphotonic Ionization}

The multiphotonic process consists of an ionization of an atom by simultaneous action of several different light quanta. If the sum of the energies of the photons is higher than the ionization energy, a free electron may be created. Keldysh (1) calculated the probability of ionization of an atom in an alternative electromagnetic field. For high frequencies of the incident field (higher than $10^{13} \mathrm{sec}^{-1}$, which is realized in the case of the Nd:YAG laser : $\omega=1.8 \times 10^{15} \mathrm{sec}^{-1}$ ), Keldysh gives the probability for direct and resonant transitions (resonant means a two-step process with one resonant intermediate state). Applied to our experimental conditions (power $P=10^{5} \mathrm{~W}$ and focal radius $R=100 \mu \mathrm{m}$ ), the calculated probability (w) to obtain one free electron in the focal volume is

$$
\begin{aligned}
w & =10^{-18} \text { per second for direct transitions, } \\
\text { and } & w=10^{-7} \text { per second for resonant transitions. }
\end{aligned}
$$

These probabilities are too low to explain the formation of the first free electrons by the multiphotonic process.

Moreover, this is confirmed by Bebb and Gold's works (2). They used a $\mathrm{n}^{\text {th }}$ order perturbation theory with a semi-classical hamiltonian to calculate the cross sections and thus to estimate the threshold fluences for ionization of pur gases. Applied to Xenon $\left(E_{i o n}=12.1 \mathrm{eV}\right.$, so that 8 photons are needed to ionise one atom), this theory leads to theorical threshold fluences around $10^{12} \mathrm{~W} / \mathrm{cm}^{2}$, whereas our experimental conditions are about 4 order of magnitude lower : $10^{8} \mathrm{~W} / \mathrm{cm}^{2}$.

Such differences between theory and practice are partly due to the simplified modelisation of the tissues that we use. Biological tissues contain macromolecules which, even after vaporization, present complexe networks of energy levels with a lower ionization energy and much more intermediate resonant states than monoatomic gases. Although these features may lower the theoretical threshold values, there still exists a two order of magnitude difference between practice and theory.

\section{Thermo-ionization}

Multiphotonic ionization seems thus to be less likely than the thermo-ionization which is the natural formation of ions and free electrons in a heated gas. This process can be modelised by the Saha's equation which governs the free electron density as a function of temperature:

$$
\mathrm{N}_{0}-\mathrm{n}_{\mathrm{e}}=\mathrm{n}_{\mathrm{e}}^{2} \frac{1}{2}\left(\frac{\mathrm{h}^{2}}{2 \pi \mathrm{mkT}}\right)^{3 / 2} \cdot \exp \left(\chi_{\mathrm{L}} / \mathrm{kT}\right) \quad \text { with }\left[\begin{array}{l}
\mathrm{N}_{0}: \text { initial atom density } \\
\mathrm{n}_{\mathrm{e}}: \text { free electron density } \\
\chi_{\mathrm{I}, 0} \text { ionization energy } \\
\mathrm{m}: \text { electron mass } \\
\mathrm{T}: \text { Temperature }
\end{array}\right.
$$

According to this equation, a temperature of $1000^{\circ} \mathrm{K}$ is sufficient to create one free electron in the focal volume in the case of the calcium $\left(E_{i o n}=6.1 \mathrm{eV}\right)$. The total energy we deposit on the focal surface can generate such a temperature if the absorption length is smaller than $1 \mathrm{~mm}$ (the higher the absorption length, the lower the final temperature).

This value is much higher than the measured ones for calculi (roughly $100 \mu \mathrm{m}:$ (3)) and fits well the characteristics of atheroma (from $500 \mu \mathrm{m}$ to $5 \mathrm{~mm}$ ). Unlike the multiphotonic mechanism, thermo--ionization seems able to initiate the plasma by creating the first free electrons. 


\section{3- FXPANSTON OF THE PIASMA}

\section{Mechanisms}

The energy of the primary free electrons is increased by absorption of light quanta. The inverse bremsstralhung mechanism must occur [ $\mathrm{E}_{\mathrm{ion}} / \mathrm{hv}$ ] times before the electron energy reaches the ionization energy. Once $\mathrm{E} \approx \mathrm{E}_{\text {ion, }}$, the electron can use its energy to ionize an atom during an inelastic collision. If we take the symbols $\mathrm{A}$ for the atom, $\mathrm{e}$ - for the free electron and hv for the photon, the global process of ionization can be written as follows:

$$
\begin{array}{llll}
\text { 1/ } & \mathrm{A}+\mathrm{e}^{-}(\mathrm{E})+\mathrm{h} v & -\cdots & \mathrm{A}+\mathrm{e}^{-}(\mathrm{E}+\mathrm{h} v): \text { repeated until } \mathrm{E} \geq \mathrm{E}_{\text {ion }} \\
2 / & \mathrm{e}^{-}\left(\mathrm{E} \approx \mathrm{E}_{\text {ion }}\right)+\mathrm{A} & -\cdots> & \mathrm{A}^{+}+2 \mathrm{e}^{-}
\end{array}
$$

By this process, each free electron can create two free electrons, thus generating an avalanche ionization with an exponantial evolution law.

However, losses can perturbate this mechanism:

- Electrons may get out the focal volume if their mean free path is longer than the focal dimensions (this occurs in case of low pressure gases).

- An electron with an energy slightly lower than the ionization energy may excite an atom with no ionization, thus loosing its energy without creation of another free electron.

- During each elastic collision (inverse bremsstralhung), part of the momentum of the electron is transferred to the atom (conservation of the momentum), thus lowering the gain of energy at each process.

In medium and high pressure gases (roughly $1 \mathrm{kbar}$ ), the losses are mainly due to elastic collisions, and can be estimated to be $-\frac{2 m}{M}$.E for each shock.

\section{Threshold Fields}

Using a model presented by Raizer (4), we can calculate the rate of growth of the energy of the free electron (E) :

$$
\frac{\mathrm{dE}}{\mathrm{dt}}=\left[\frac{\mathrm{e}^{2} \cdot \mathrm{E}_{0}^{2}}{2 \cdot \mathrm{m}\left(\omega^{2}+\mathrm{v}_{\mathrm{m}}^{2}\right)}-\frac{2 \cdot \mathrm{m}}{\mathrm{M}} \cdot \mathrm{E}\right] \cdot v_{\mathrm{m}} \quad \text { with } \quad\left[\begin{array}{l}
\mathrm{E}_{0}: \text { incident field } \\
\omega: \text { incident field frequency } \\
\mathrm{m}: \text { electron mass } \\
\mathrm{M}: \text { atom mass } \\
v_{\mathrm{m}}: \text { collision frequency }
\end{array}\right.
$$

The expansion of the plasma needs the electron to be accelerated, so that $\frac{\mathrm{dE}}{\mathrm{dt}}>0$, which imposes a maximum energy. The condition of ionization suposes to have the mean energy of the electron (which is roughly equal to the third of the maximum energy) higher than the ionization energy. The threshold fields for the plasma expansion are then around $4 \times 10^{8} \mathrm{~V} / \mathrm{m}$. It is in good agreement with our experimental conditions $\left(E_{0}=5 \times 10^{8} \mathrm{~V} / \mathrm{m}\right)$ because of the lack of accurate measures of the collision frequency in a non homogeneous gas. 


\section{4-SBOCK MAVFS}

\section{Propagation modes}

The plasma expansion generates shock waves of pressure and temperature. These waves propagate by three different means:

- The breakdown wave: If the laser beam is focalized, the flux will be higher at the focal point than near the source (because of a larger diameter near the exit of the laser). The breakdown will then develop earlier at the focal point, thus generating a fictive wave front retrogradly propagating in the laser beam.

- The detonation wave, thus named because of its similarity with the detonation process during which the shock wave is used to initiate the chemical reaction which will provide the wave front with energy. In the case of laser-tissues interaction, the shock wave heats, vaporizes and partially ionizes the cold layers through which it passes. Although these layers weakly absorbed the laser light while there were cold, they can now absorbe it and achieve their transformation into plasma. This ultra-fast process pushes forward the wave front.

- The radiation wave : It consists of the same processes than the detonation wave, but the initial heating, vaporization and ionization is performed by the light emission of the plasma: like every hot body (from $10,000^{\circ} \mathrm{K}$ to $20,000^{\circ} \mathrm{K}$ ), the plasma emits light at a wavelength ( $100 \mathrm{~nm}$ to $300 \mathrm{~nm}$ ) easily absorbed by the cold matter, which is thus converted into weakly ionized vapor.

The plasma will not develop out of the laser beam because it needs the laser energy to propagate, but the shock waves can expand radially in the surrounding matter (either the tissues or the liquid). We can apply the equations of fluid mechanics to calculate the velocity of the detonation wave in water :

$$
D=\left[\frac{2 \times\left(\gamma^{2}-1\right) \times S_{0}}{\rho_{0}}\right]^{1 / 3} \text {, with }
$$

So that $\mathrm{D}=1700 \mathrm{~m} / \mathrm{s}$

$$
\begin{aligned}
& -\rho_{o}=\text { water specific mass }=1000 \mathrm{~kg} / \mathrm{m}^{3}, \\
& \gamma=1.33 \\
& - \text { So }=\text { laser fluence }=3.2 \times 10^{12} \mathrm{~W} / \mathrm{m}^{2}
\end{aligned}
$$

These results are close to the experimental measurements (5). The spatial and temporal evolution of the shock waves can be estimated by measuring the absorption features of the surrounding liquid by the mean of a second laser, or by ultra fast photographies of the system. The wave front velocity is reported to be supersonic $(\approx 2200 \mathrm{~m} / \mathrm{s})$ during the pulse duration. Once no more energy is supplied by the laser to maintain a supersonic regime, the speed decreases downto the sound velocity $(\approx 1500 \mathrm{~m} / \mathrm{s})$. The pressure is measured by captors which give a mean value ranged from 0.6 to $1 \mathrm{kbar}(5)$.

\section{Cavitation}

The shock waves induce a radial liquid movement from the focal point, thus creating a depression which favorizes the vaporization of the tissues by the heat diffusing from the cooling plasma, and the formation of a gas bubble. The cavitation process starts $\approx 50 \mathrm{~ns}$ after the beginning of the laser pulse. The gas bubble expands with a mean velocity equal to roughly $40 \mathrm{~m} / \mathrm{s}$, until it reaches its maximum size $(\approx 0.8$ to $1 \mathrm{~mm}$ ) at the time $t \approx 300 \mu \mathrm{s}$. Then it collapses with a velocity equal to $11 \mathrm{~m} / \mathrm{s}$ until it disappears at $\mathrm{t} \approx 700 \mu \mathrm{s}$.

\section{5-ACTIONS ON BIOLOGICAL TISSUES}

Now we shall try to explain the observed actions of the laser on tissues.

- Calculi are fragmented into macroscopic pieces, which can be as big as $2 \mathrm{~mm}$. It seems to be a purely mechanical action, revealing the discontinuity or the free surfaces of the stone (which are also the weakest parts of the stone). No signs of burns are shown, even with microscopic studies. 
- Atheroma is transformed into microscopic fragments, which allow us to think at a very localized "thermal" action. But no signs of necrosis or burns are shown on the walls of the crater formed by the ablated matter.

Mechanical effects are mostly due to the depression waves: calculi are more sensible to tractive efforts than to compressive efforts. Tensile waves are generated by the cavitation mechanism (collapse of the gas bubble) or by reflection of the compression waves on a free or a discontinuity surface (6) : to satisfy the boundary conditions, a negative pressure wave is launched at the free surface and propagates retrogradly against the initial wave. Once the tensile and the compression waves no longer cancel each other, the former is efficient and can fragment the stone.

In consideration of the high temperatures reached in the plasma $\left(10,000^{\circ} \mathrm{K}\right.$ to $\left.20,000{ }^{\circ} \mathrm{K}\right)$, we can not neglect thermal effects. However, the plasma limits the dommages by two different means:

- It absorbes the whole incident energy on a very thin layer, so that the energy can not deposit deeper in the tissues. The thermal effects will then be much more localized than in continuous wave laser irradiation.

- The shock waves and the cavitation process use an important part of the energy to develop, thus reducing the thermal energy which could have diffused in the healthy tissues.

\section{6-CONCIUSION}

The plasma appears to be an indispensable condition to obtain electromechanical effects. We showed that the thermal ionization hypothesis seems in good agreement with our experimental conditions, whereas the multiphotonic process may not play an important role in the formation of the plasma with the fluences we use.

The modelisation of the propagation of the shock waves gives theoritical results close to the measurements, and may help us to understand and quantify the mechanical actions on the biological tissues.

Although the effects of the breakdown are obvious in the case of the calculi, no sign of mechanical action is shown for atheroma (the tissue which is not ablated seems to be excactly like before the laser pulse). The ablation of tissues in this case might be mainly due to the high temperatures created at the focal point, and to vaporization of the layers surrounding the plasma. The plasma seems to be very useful to localize the heat action in a small volume ( $\mathrm{a}$ few tenths of microns) and to dissipate the excess of energy by mechanical means. The abscence of necrosis might be imputed to mechanical effects which would clean the walls of the crater.

I would like to thank Mr Jean Virmont (lab. P.M.I. of Ecole Polytechnique) for helpful discussions.

\section{References}

1- L.V.KELDYSH. Sov. Phys. JETP 20, 1965; 5; 1307-1314.

2- A. GOLD and H.B. BEBB. Phys. Rev. Letters 14, 1965; 3; 60-63.

3- F.H. LONG et al.. Lasers in Surgery and Medecine 1987; 461-466.

4- Yu.P. RAIZER: Laser-induced discharge phenomena. Consultants Bureau, New-York; 1977.

5- P. TENG et al.. IIIE QE23, 1987; 1845-1852.

6- S.J. GITOMER et al.. Lasers in life science. 